\title{
The Time Has Come for Pediatric Dentistry and Medicine to Develop A New Thought Process, Rather Than Just Thinking Outside the Box When Caring for Newborn Babies and Infants, We Need A Totally New Box
}

\author{
Lawrence Kotlow DDS* \\ Department of Pediatric Dentistry, USA \\ *Corresponding author: Lawrence Kotlow DDS, Department of Pediatric Dentistry, 340 Fuller Road Abany NY, USA
}

\section{Introduction}

The concept of thinking outside the box is no longer valid, we now need to create a new box. The volumes of research showing the merging of medicine and dentistry is growing rapidly and those who fail to grasp its importance will be left behind. Our primary goal in caring for newborn infants and babies should be to allow them to grow and develop to their maximum potential. It's time for the old, outdated conservative ideas, to be shed and have the Dental and Medical community understand that the separation of medicine and dentistry is rapidly disappearing.

\section{Collaboration does not turf concerns}

The primary example of this is in the diagnosis and treatment of tethered oral tissues also known as TOTS. In the early 1970's less than $22 \%$ of US women were breastfeeding their newborn infants, many who were, did so because they could not afford the cost of infant milk formulas [1]. The formula industry has always advertised the benefits of their product over mother's milk and since so few mothers were nursing, difficulties of nursing due to tongue or lip ties were dismissed or just plain ignored by the medical providers. Today, we have over $80 \%$ of mothers breastfeeding, we also are aware of the many long-term benefits for both the infant and mother. We also know that mothers who wish to breastfeed include all socioeconomic levels of society. It is not a fad as many in the medical community refer to treatment of TOTs.

Yet, the medical community still all too often rejects the idea that TOTS do prevent a baby from achieving a good secure attachment to a mother's breast, resulting in a plethora of symptoms for both mother and infant, often resulting in the mother giving up and using a bottle. Some explain this failure of the Medical community to embrace the release of these TOTS as overstepping our scope of practice and consider it their turf, yet they do nothing. The effects of TOTS begin in the oral cavity, where we as pediatric dentists, are the experts. Improving the health care of mothers and infants and should not involve turf wars and protectionism for physicians and dentists. We need to effectively join forces to create a successful breastfeeding outcome. Dentistry and medicine treat the same entity, where often one or many health problems can overlap into both professions' territory. This is a key reason why Medicine needs to develop a cooperative team approach to breastfeeding issues with Dentists $[2,3]$. The understanding in treating infant oral health is growing and changing, this presents an excellent opportunity for physicians and dentists to find ways in to effectively join forces to create a successful breastfeeding outcome.

\section{Infant- Mother Bonding}

It is time to look beyond just the infant's latch, but the actual potential complication that a poor latch creates beyond the act of breastfeeding comfortable for the Mother. Medicine recognizes the term attachment theory, which states that the babies initial bonding with the mother lasts a lifetime, if it is short circuited, the mother may develop signs of post-partum depression, which rather than treating symptoms pharmacologically, in many cases this may be resolved if we, as pediatric dentists can fix the inability of the infant to latch onto the breast by a simple in office surgical release, not just a simple snip, known as a frenectomy [4]. Breastfeeding plays an integral role in forming the deep attachment between mother and baby.

\section{Failure to thrive}

Infants are far too often placed in hospitals for failure to thrive, parents are occasionally subjected to Child abuse accusations because their child appears malnourished, and in severe cases have had nasal-gastric or tubes inserted directly into the stomach 
surgically to literally force feed infants [5]. All this has happened because the physician, pediatrician, ENT or GI doctors never even consider the ankylosed tongue as the primary cause.

\section{Brain growth and development}

The window of opportunity to help many babies may close with-in the first 90 days after the infant's birth [6]. Studies indicate that a baby's brain grows by 1 percent each day beginning right after birth. A newborn brain grows extraordinarily fast right after birth but slows down to a growth rate of 0.4 percent per day by the end of three months. An infants' brains grow by 64 percent in the first 90 days, according to the study. The average brain size was 20 cubic inches (341 cubic centimeters) at birth, and 34 cubic inches (558 cubic $\mathrm{cm}$ ) at 90 days. Simply stated, the brains of newborns grew from about 33 percent of the average adult brain doubles in size in the first year, and by age three it has reached $80 \%$ of its adult volume.

\section{Air induced reflux}

It was those hellish hours between darkness and dawn when my husband and I would take turns walking around the house with our baby inn our arms, praying and, mostly in my case, sobbing because we couldn't console our baby. Infants suffering from reflux are still being treated with adult anti-reflux drugs rather than looking a t the most likely source of gas build up, the swallowing of air during the infant's latch due to a poor latch and seal onto the mother's breast. Adult pharmaceuticals such as Peracid and Nexium are not approved drugs for children under age one [7-10]. Studies show they are not effective. Yet the use is skyrocketed in recent years. Simply releasing TOTS will allow a good secure latch to occur in most infants, quickly resolving the issue. Medications like ranitidine (Zantac) or omeprazole (Prilosec) can prevent absorption of calcium and iron and increase the risk of certain intestinal and respiratory infections. Children who used PPIs had a $22 \%$ increased likelihood of fracture, while children who used both PPIs and H2-blockers had a 31\% increased likelihood of fracture.

\section{Sleep disordered breathing}

Tethered oral tissues (TOTS) is also a common undiagnosed source of obstructive airway problems, obstructive sleep apnea and reflux in infants and newborns [11-16]. The American Academy of Pediatric Dentistry (AAPD) recognizes that obstructive sleep apnea (OSA) occurs in the pediatric population. In order to reduce such complications, AAPD encourages healthcare professionals to routinely screen their patients for increased risk for OSA and to facilitate medical referral when indicated The most common form of Pediatric OSA is a disorder of breathing characterized by prolonged, partial upper airway obstruction and or intermittent/ complete obstruction (obstructive apnea) that disrupts normal ventilation during sleep and normal sleep patterns. These cycles of awakening prohibit the infant as well as toddlers having apnea from reaching deep, restful sleep. For this reason, children with untreated OSA may be inappropriately diagnosed as having ADHD. Often the ankylosed tongue is again ignored and not considered as a part of a differential diagnosis. Findings from studies that used complementary research methods have converged to strongly suggest that inadequate sleep quality and quantity are causally linked to sleepiness, inattention, and probably other cognitive and behavioral deficits that impact daytime functioning, with potential implications for long-term development.

\section{Conclusion}

It has been stated that it can take a 17-year lag to change and understand traditional research. This lack of knowledge puts those responsible for enabling new research at a disadvantage [17]. A staggering 36,000 randomized controlled trials (RCTs) are published each year, on average, and it typically takes about 17 years for findings to reach clinical practice [18]. We do not have this time to waste in treating our infants and newborns. We need to establish a good collaboration and trust between our two professions and develop a good understanding of how tethered oral tissues can have a significant impact on the overall growth and development of newborns and infants [19].

\section{References}

1. Wright A, Schanler R (2001) The resurgence of breastfeeding at the end of the Second Millennium j of American Society for Nutritional Sciences. Journal of Nutrition 131(2): 421-425.

2. Notestine GE (1990) The importance of theidentification of ankyloglossia (a short lingual frenum) as a cause of breastfeeding problems. J Hum Lact 6(3): 113-115.

3. Marmet C, Shell E, Marmet R (1990) Neonatal frenotomy may be needed to correct breastfeeding problems. J Hum Lactation 6(3): 117-121.

4. Lyons RK, Easterbrooks MA, Cibelli CD (1997) Infant attachment strategies, infant mental lag, and maternal depressive symptoms: Predictors of internalizing and externalizing problems at age 7. Dev Psychol 33(4): 681-692.

5. Gregory PF, Nicole M, Paradise B, Elayne G, Sandra ES (2010) Ankyloglossia, Exclusive Breastfeeding, and Failure to thrive. Pediatrics 125(6): 1500-1504.

6. Dominic H (2014) Multimodal Imaging Laboratory and Department of Neurosciences, University of California, USA.

7. Dominic H, Linda C, Thomas M Ernst, Megan Cu, Steven DB, et al. (2014) Structural Growth Trajectories and Rates of Change in the First 3 Months of Infant Brain Development. JAMA Neurol 71(10): 1266-1274.

8. Lawrence Kotlow (2016) Breastfeeding and Tethered Oral Tissues: Air Induced Reflux and Obstructive Sleep Apnea. EC Paediatrics 3(3): 356365.

9. Kotlow L (2011) Infant reflux and aerophagia associated with the maxillary lip-tie and ankyloglossia (tongue-tie). Clin Lact 2(4): 25-29.

10. Siegel S (2016) Aerophagia induced reflux in breastfeeding infants with ankyloglossia and shortened maxillary labial frenula (tongue and lip tie). Int J Clin Pediatr North Am 5(1): 6-8.

11. Randel A (2014) AAP Releases Guideline for the Management of Gastroesophageal Reflux in Children. Am Fam Physician 89(5): 395-397.

12. (2013) AAP Releases Guideline for the Management of Gastroesophageal Reflux in Children Pediatrics 131: 1684-1695.

13. (2012) American Academy of Pediatrics. Clinical practice guideline on the diagnosis and management of childhood obstructive sleep apnea syndrome. Pediatrics 130(3): 576-684.

14. Padmanabhan V, Kavitha PR, Hedge AM (2010) Sleep disordered breathing in children-A review and the role of the pediatric dentist. J Clin Ped Dent 35(1): 15-21. 
15. Chervin RD, Archbold KH, Dillon JE, Panahi P, Pituch KJ, et al. (2002) Inattention, hyperactivity, and symptoms of sleep-disordered breathing Pediatrics 109: 449-456.

16. Yu Shu Huang, Stacey Quo, J Andrew Berkowski, Christian Guilleminault (2015) Short Lingual Frenulum and Obstructive Sleep Apnea in Children Int J Pediatr Res 1:1.

17. Karen Bonuck, Katherine Freeman, Ronald D Chervin, Linzhi Xu (2012) Sleep-Disordered Breathing in a Population-Based Cohort: Behavioral Outcomes at 4- and 7-Years Pediatrics 129(4): 857-865.
18. Christian Guilleminault, Farah Akhtar (2015) Pediatric sleep-disordered breathing: New evidence on its development. Sleep Medicine Reviews 24: 46-56.

19. Zoë Slote Morris, Steven Wooding, Jonathan Grant (2011) The answer is 17 years, what is the question: understanding time lags in translational research. J R Soc Med 104(12): 510-520.

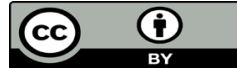

This work is licensed under Creative Commons Attribution 4.0 License

To Submit Your Article Click Here: Submit Article

DOI: $10.32474 /$ IPDOAJ.2019.03.000167

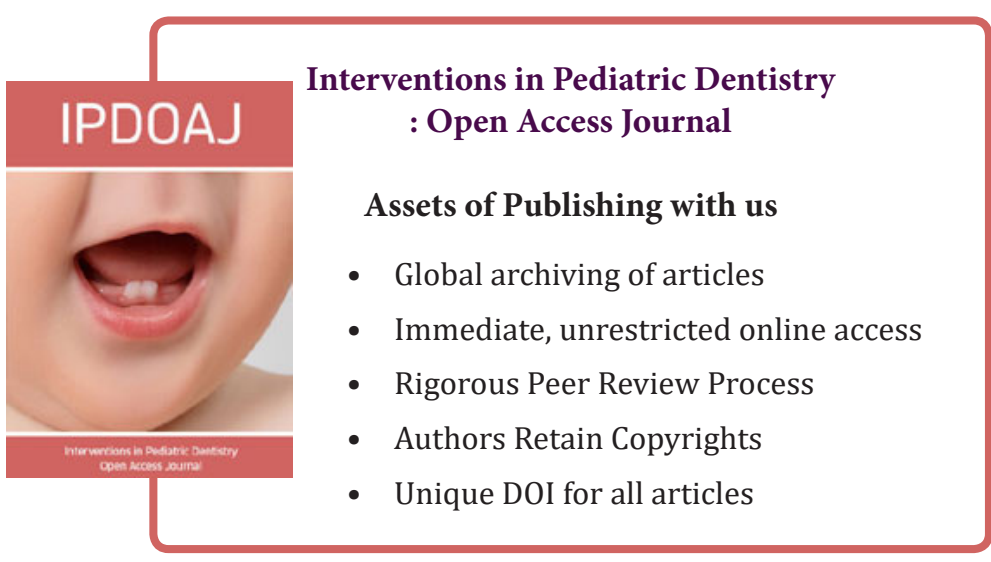

